\title{
Relationship between Hemoglobin Alc and Fractional Flow Reserve Lesion Severity in Non-diabetic Patients
}

\author{
Mehmet Kis $^{1}$ and Tuncay Guzel ${ }^{2}$ \\ ${ }^{1}$ Department of Cardiology, Silopi State Hospital, Sirnak, Turkey \\ ${ }^{2}$ Department of Cardiology, Health Science University, Gazi Yaşargil Training and Research Hospital, Diyarbakır, Turkey
}

\begin{abstract}
Objective: To find out whether there is any correlation between the fractional flow reserve (FFR) that indicates the severity of coronary artery disease (CAD), and the HbAlc value in non-diabetic patients.

Study Design: Observational study.

Place and Duration of Study: Department of Cardiology, Dicle University, Turkey, from September 2015 to November 2019.

Methodology: Patients who underwent elective FFR procedure were included in the study. There were two groups formed according to FFR lesion severity: FFR $<0.8$ group (75 patients), FFR $>0.8$ group (39 patients). HbAlc was compared between the two groups. The relationship between categorical variables was examined with Pearson Chi-square and Fisher's Exact test. ROC (Receiver operating characteristic) analysis was performed for the HbAlc the cut-off value.

Results: The two groups were similar in terms of mean age and male gender ratios $(58.4 \pm 9.6$ vs. $57.9 \pm 10.8$ years, $p=0.794 ; 64 \%$ vs. $74.4 \%$, respectively, $p=0.262$ ). HbAlc value was statistically higher in the group with FFR value <0.8 [(5.8 (IQR: 5.7-6.0)] compared to the group with FFR value $\geq 0.8$ [(5.5 (IQR: 5.2-6.0, $p=0.002)$ ]. The HbAlc cut-off value was determined as 5.55. The ideal HbAlc threshold value calculated by the Youden index had $88 \%$ sensitivity, and $53.85 \%$ specificity.

Conclusion: $\mathrm{HbAlc}$, which shows the long-term glycemic index in non-diabetic individuals, is associated with the severity of CAD determined by the fractional flow reserve.
\end{abstract}

Key Words: Coronary artery disease, fractional flow reserve, $\mathrm{HbAlC}$.

How to cite this article: Kis M, Guzel T. Relationship between Hemoglobin Alc and Fractional Flow Reserve Lesion Severity in Non-diabetic Patients. J Coll Physicians Surg Pak 2022; 32(01):4-8.

\section{INTRODUCTION}

Coronary artery disease (CAD), characterised by atherosclerotic plaque accumulation in the epicardial arteries, is one of the leading causes of morbidity and mortality worldwide. ${ }^{1}$ Although coronary angiography (CAG) is the gold standard in the diagnosis of CAD, it cannot show whether the lesion causes ischemia, and cannot show arterial vessel wall, or plaque burden in patients with moderate stenosis. ${ }^{2}$ Therefore, fractional flow reserve (FFR) is an importantinterventionaldiagnosticmethod to determinethefunctional significance of moderate epicardial artery stenosis (between 40-70\%) and to detect the lesion that requires intervention in $\mathrm{CAG}^{3}{ }^{3} \mathrm{As}$ a result of the measurement, the cut-off FFR value for stenosis to requiring intervention is $<0.80$. If the FFR was $>0.80$, it should be considered that the lesion was not hemodynamically serious. ${ }^{4} F F R$ is being increasingly utilised in many centres to evaluate coronary artery stenosis. In addition, FFRguided coronary revascularisation is a safe and long-term effective method. ${ }^{4,5}$

Correspondence to: Dr. Mehmet Kis, Department of Cardiology, Silopi State Hospital, Sirnak, Turkey

E-mail:drmehmet.kis@hotmail.com

Received: July 03, 2021; Revised: October 20, 2021;

Accepted: November 15, 2021

DOI: https://doi.org/10.29271/jcpsp.2022.01.4
Hemoglobin $\mathrm{Alc}(\mathrm{HbAlc})$, is one of the endogenous advanced glycation-end products (AGE), and it is a parameter that shows the long-term mean glycemic index. Determination of $\mathrm{HbAlc}$ does not require fasting state or glucose loading; and it is a parameter that provides a single-sample glycemia determination with higher reproducibility than fasting glucose. ${ }^{6}$ It was stated that besides the diagnosis of diabetes mellitus, $\mathrm{HbAlc}$ was strongly associated with CAD and can be used as a marker of $C A D$, and also predicts cardiovascular disease and mortality in patients without diabetes mellitus. ${ }^{6-8}$

The correlation between CAD severity and HbAlc levels in patients with diabetes mellitus is well understood. However, the relationship between $\mathrm{HbAlc}$ levels and CAD severity in patients without diabetes mellitus is still controversial. ${ }^{9,10}$

The aim of this study was to investigate whether there is any correlation between the FFR, which indicates CAD severity, and $\mathrm{HbAlc}$ in the non-diabetic adult population; and find the ideal cut-off value of $\mathrm{HbAlc}$ for better risk stratification and prediction of CAD occurrence in non-diabetic patients.

\section{METHODOLOGY}

This observational study was conducted at Department of Cardiology, Medical Faculty, Dicle University from September 2015 to November 2019. Patients, who underwentelective FFR proce- 
dure, were included in this study. Ethics Committee approval was obtained from Faculty of Medicine, Bakırçay University (Decision No. 263). Demographic characteristics, such as age, gender, blood pressure, and heart rate were recorded. There were two groups, according to FFR lesion severity as FFR $<0.8$ group (75 patients), FFR $>0.8$ group (39 patients).

Patients with no previous history of diabetes mellitus, fasting blood glucose $<126 \mathrm{mg} / \mathrm{dl}$, and $\mathrm{HbAlc}<6.5 \%$ were included in the study. Patients younger than the age of 18 and older than the age of 90 years, those with a history of diabetes or HbAlc level above $6.5 \%$, or a history of previous revascularisation, who had severe renal failure and severe liver failure, anemic patients ( $\mathrm{Hb}$ values below $10 \mathrm{mg} / \mathrm{dl})$, and active malignancy, were excluded from the study.

IBM SPSS Statistics version 21.0 programme was used. The suitability of numerical variables to normal distribution was examined, using the Shapiro-Wilk and Kolmogorov-Smirnov tests. Numerical variables are given as mean and standard deviation. For a comparison between the two groups in terms of numerical variables, if normal distribution was achieved independent samples t-test was used; if not, Mann-Whitney U-test was used. Categorical variables were shown as numbers $(n)$ and proportions (\%). Median and interquartile range (IQR) $25^{\text {th }}-75^{\text {th }}$ percentiles values were given for non-parametric findings. The relationship between categorical variables was examined with Pearson Chi-square and Fisher's Exact test. ROC (Receiver operating characteristic) analysis was performed for the HbAlc cutoff value. The cut-off was determined, according to Youden index. The significance level was accepted as $<0.05$ for all hypotheses.

G Power 3.0.8 programme was done for the sample size calculation. Estimated sample size was calculated using Student's-t test with $80 \%$ power, $\alpha=0.05$ error level and Cohen (d) effect size $=0.8$. Accordingly, it was found appropriate to complete the study with at least 52 patients. G Power 3.1.9.7 programme was used for post hoc power. Difference between two independent means test was applied. The power (1- $\beta$ err probe) was determined as 0.986 with alpha 0.05 error level, Cohen (d) effectsize $=0.8$.

\section{RESULTS}

The mean age of the 114 patients included in the study, who had a moderate coronary lesion documented by CAG (coronary angiography) and had FFR to determine the severity of the lesion, was $58.2 \pm 9.3$ years, and $68 \%$ of the patients were males. The group with FFR lesion severity $<0.8$ consisted of 75 $(65.8 \%)$ patients, and the group with FFR lesion severity $\geq 0.8$ consisted of 39 (34.2\%) patients. The groups were similar in terms of mean age and male gender ratios (58.4 \pm 9.6 vs. $57.9 \pm$ $10.8, p=0.794 ; 64 \%$ vs. $74.4 \%$, respectively, $p=0.262$, Tablel).

When both groups were compared in terms of comorbidities, no significant difference was found for hypertension $(42.7 \%$ vs. $48.7 \%, p=0.538)$, previous CAD (49.3\% vs. $43.6 \%, p=0.560)$, and hyperlipidemia ( $54.7 \%$ vs. $59.0 \%, p=0.660)$. The comorbid conditions of the study population is summarised in Table I. Biochemical and echocardiographic parameters were similar in both groups. This result shows that the patient groups are homogeneously distributed. The laboratory and imaging findings of the patients are summarised in Tablell.

The $\mathrm{HbAlc}$ median value in the group with FFR value $<0.8$ (5.8 (IQR: 5.7-6.0)) was statistically higher than the group with FFR value $\geq 0.8$ [(5.5 (IQR: 5.2-6.0, $p=0.002)]$. The mean HbAlc value is $5.73 \pm 0.36$. In the ROC analysis applied considering the Youden index and associated criterion (Figure 1), HbAlc >5.55 had $88 \%$ sensitivity and $54 \%$ specificity (ROC area under curve: $0.68,95 \% \mathrm{Cl}: 0.569-0.791, \mathrm{p}=0.002$ ) for determining the coronary stenosis severity.

The history of medicines use before the FFR procedure was similarin both groups.

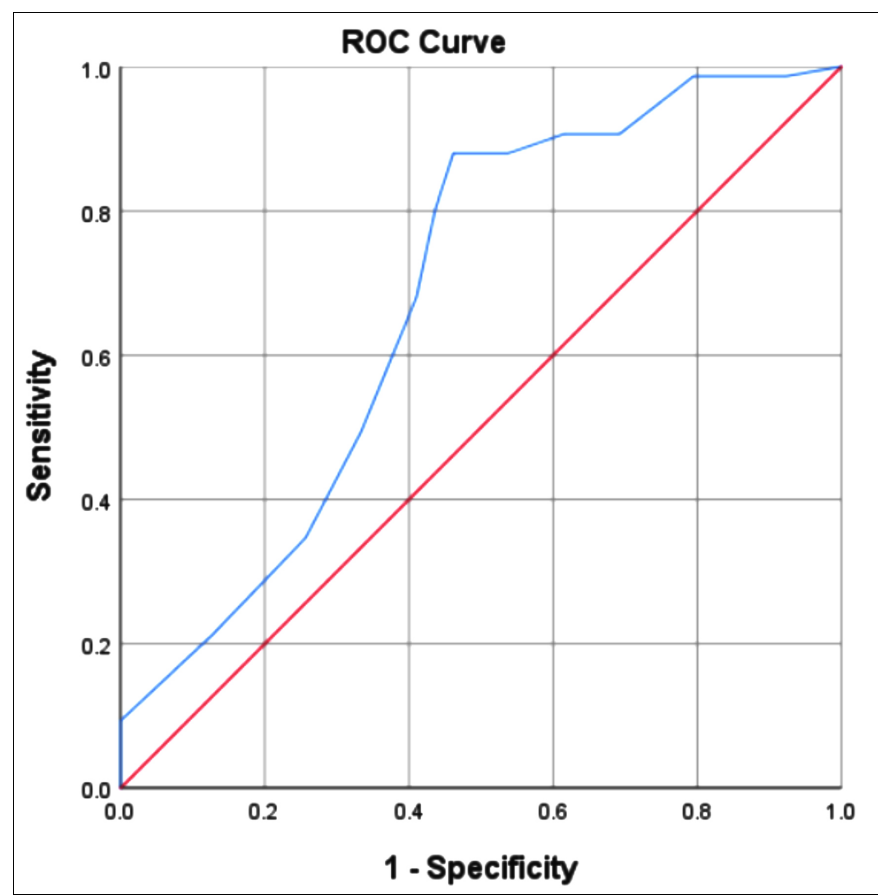

Figure 1: The cut-off value of HbAlc associated with FFR in the ROC curve.

\section{DISCUSSION}

To the best of authors' knowledge, this is the first study in the literature to evaluate the correlation between coronary artery lesion severity determined by FFR and $\mathrm{HbAlC}$ value in non-diabetic patients. In this study, the mean $\mathrm{HbAlc}$ levels were significantly higher in the patient group with low FFR compared to the group with high FFR $(p<0.001)$ and there was a strong correlation.

In this study, the authors thought to use FFR findings instead of CAG findings in order to provide more meaningful findings. ${ }^{11}$ $\mathrm{HbAlc}$ is one of the endogenous AGEs and is a parameter that indicates the long-term mean glycemic index. In a study evaluating the relationship between $\mathrm{HbAlc}$ and blood glucose levels in 131 cases, it was stated that there was a correlation between the mean blood glucose value and $\mathrm{HbAlc}$ values, and this correlation was extremely important in terms of CV mortality and morbidity, as well as in the follow-up ofDM. ${ }^{12}$ 


\begin{tabular}{|c|c|c|c|c|}
\hline & $\begin{array}{c}F F R<0.8 \\
(n=75)\end{array}$ & $\begin{array}{c}\text { FFR }>0.8 \\
(n=39)\end{array}$ & $\begin{array}{c}\text { Total } \\
(n=114)\end{array}$ & p-value \\
\hline Age (years) & $58(51-66)$ & $57(49-65)$ & $58(51-66)$ & 0.794 \\
\hline Male gender, n (\%) & $48(64)$ & $29(74.4)$ & $77(67.5)$ & 0.262 \\
\hline $\mathrm{SBP}, \mathrm{mmHg}$ & $127(116-135)$ & $130(110-140)$ & $128(112-140)$ & 0.824 \\
\hline $\mathrm{DBP}, \mathrm{mmHg}$ & $70(60-80)$ & $70(60-80)$ & $70(60-80)$ & 0.836 \\
\hline Heart rate, $\min$ & $70(62-78)$ & $77(65-85)$ & $72(63-82)$ & 0.169 \\
\hline NYHA Class I, n (\%) & $71(94.7)$ & $38(97.4)$ & $109(95.6)$ & 0.493 \\
\hline Chest pain, $\mathrm{n}(\%)$ & $69(92)$ & $35(89.7)$ & $104(91.2)$ & 0.686 \\
\hline Dyspnea, n (\%) & $15(20)$ & $10(25.6)$ & $25(21.9)$ & 0.490 \\
\hline Palpitation, n (\%) & $5(6.7)$ & $9(23.1)$ & $14(12.3)$ & 0.011 \\
\hline Fatigue, $\mathrm{n}(\%)$ & $6(8)$ & $7(17.9)$ & $13(11.4)$ & 0.113 \\
\hline Dizziness, n (\%) & $4(5.3)$ & $2(5.1)$ & $6(5.3)$ & 0.963 \\
\hline Syncope, n (\%) & $1(1.3)$ & $0(0)$ & $1(0.9)$ & 1.000 \\
\hline Smoking, $\mathrm{n}(\%)$ & $27(36.0)$ & $17(43.6)$ & $44(38.6)$ & 0.430 \\
\hline Alcohol use, n (\%) & $4(5.3)$ & $2(5.1)$ & $6(5.3)$ & 0.963 \\
\hline Hypertension, n (\%) & $32(42.7)$ & $19(48.7)$ & $51(44.7)$ & 0.538 \\
\hline CAD, n (\%) & $37(49.3)$ & $17(43.6)$ & $54(47.4)$ & 0.560 \\
\hline Hyperlipidemia, n (\%) & $41(54.7)$ & $23(59.0)$ & $64(56.1)$ & 0.660 \\
\hline COPD, n (\%) & $10(13.3)$ & $8(20.5)$ & $18(15.8)$ & 0.319 \\
\hline Thyroid disease, n (\%) & $6(8.0)$ & $4(10.3)$ & $10(8.8)$ & 0.686 \\
\hline Stroke/TIA & $7(9.3)$ & $2(5.1)$ & $9(7.9)$ & 0.430 \\
\hline CKD, n (\%) & $3(4.0)$ & $2(5.1)$ & $5(4.4)$ & 0.780 \\
\hline Peripheral artery disease & $4(5.3)$ & $1(2.6)$ & $5(4.4)$ & 0.493 \\
\hline Pacemaker / ICD / CRT & $2(2.7)$ & $0(0)$ & $2(1.8)$ & 0.546 \\
\hline Anemia, n (\%) & $1(1.3)$ & $1(2.6)$ & $2(1.8)$ & 1.000 \\
\hline
\end{tabular}

Table II: Biochemical and imaging findings of the patients.

\begin{tabular}{|c|c|c|c|c|}
\hline $\begin{array}{l}\text { Parameter mean ( } \pm \text { standard } \\
\text { deviation) }\end{array}$ & $\begin{array}{c}F F R<0.8 \\
(n=75)\end{array}$ & $\begin{array}{c}F F R>0.8 \\
(n=39)\end{array}$ & Total & p-value \\
\hline Urea, $\mathrm{mg} / \mathrm{dL}$ & $32(28-37)$ & $31(26-37)$ & $32(28-37)$ & 0.514 \\
\hline Creatinine, mg/dL & $0.88(0.74-1.00)$ & $0.90(0.70-1.00)$ & $0.88(0.74-1.00)$ & 0.998 \\
\hline Unic acid, mg/dl & $5.3(4.6-6)$ & $5.6(5-6.10)$ & $5.4(4.6-6)$ & 0.101 \\
\hline Total cholesterol, mg/dL & $189(161-229)$ & $181(152-206)$ & $186(160-223)$ & 0.190 \\
\hline Triglyceride, mg/dl & $161(111-216)$ & $140(103-185)$ & $155(107-201)$ & 0.179 \\
\hline $\mathrm{HDL}, \mathrm{mg} / \mathrm{dL}$ & $39(31-48)$ & $41(35-51)$ & $40(33-50)$ & 0.176 \\
\hline $\mathrm{LDL}, \mathrm{mg} / \mathrm{dL}$ & $120(96-149)$ & $104(85-134)$ & $113(91-143)$ & 0.072 \\
\hline $\mathrm{WBC}, \mathrm{k} / \mathrm{mm} 3$ & $8.1(7-8.9)$ & $8.3(7-10)$ & $8.1(7-9.1)$ & 0.464 \\
\hline Hemoglobin, g/dL & $13.9(12.7-14.6)$ & $13.5(12.7-14.3)$ & $13.8(12.7-14.6)$ & 0.573 \\
\hline Platelet & $247(223-279)$ & $248(217-285)$ & $248(222-281)$ & 0.740 \\
\hline Fasting glucose, mg/dL & $101(93-106)$ & $99(89-107)$ & $100(92-107)$ & 0.468 \\
\hline $\mathrm{TSH}, \mathrm{mU} / \mathrm{L}$ & $1.74(1.08-2.8)$ & $1.96(0.74-2.97)$ & $1.88(0.94-2.88)$ & 0.935 \\
\hline T4 & $1.31(1.13-1.68)$ & $1.26(1.15-1.60)$ & $1.31(1.13-1.67)$ & 0.608 \\
\hline $\mathrm{Ca}, \mathrm{mg} / \mathrm{dL}$ & $9.4(9.1-9.8)$ & $9.2(8.9-9.6)$ & $9.3(8.9-9.7)$ & 0.330 \\
\hline Sodium & $140(138-141)$ & $140(138-142)$ & $140(138-141)$ & 0.348 \\
\hline Potasium & $4.51(4.26-4.73)$ & $4.40(4.20-4.73)$ & $4.49(4.24-4.73)$ & 0.971 \\
\hline $\mathrm{HbAlc}$ & $5.8(5.7-6)$ & $5.5(5.2-6)$ & $5.8(5.5-6)$ & 0.002 \\
\hline Sinus rhythm, n (\%) & $71(94.7)$ & $39(100)$ & $110(96.5)$ & 0.142 \\
\hline LVEF,\% & $60.00(55-60)$ & $60.00(50-60)$ & $60(54-60)$ & 0.165 \\
\hline LVEDD, cm & $46.00(44-51)$ & $48.00(44-52)$ & $47(44-51)$ & 0.281 \\
\hline LVEDS, cm & $29.00(25-32)$ & $30.00(27-34)$ & $29(25-32)$ & 0.144 \\
\hline LVDD, n (\%) & $51(68)$ & $22(56.4)$ & $73(64.0)$ & 0.221 \\
\hline \multicolumn{5}{|c|}{$\begin{array}{l}\text { Data are given in number (percentile) or median [IQR]: (25th-75th percentile). AS: Aortic stenosis; AR: Aortic regurgitation; Ca: Calcium; HbAlC: Hemoglobin } \\
\text { Alc; HDL: High density lipoprotein; LDL: Low density lipoprotein; LVDD: Left ventricular diastolic dysfunction; LVEDD: Left ventricular end diastolic diameter } \\
\text { LVESD - left ventricular end systolic diameter; LVEF - left ventricular ejection fraction; Mg - magnesium; MR - mitral regurgitation; MS - mitral stenosis; P - } \\
\text { phosphate; TSH - thyroid stimulating hormone; WBC - white blood cell. }\end{array}$} \\
\hline
\end{tabular}


In another study that included 346 patients to evaluate the relationship between $\mathrm{HbAlc}$ level and CAD severity in non-diabetic patients, it was found that as the HbAlc level increased, there was a significant increase in the mean number of diseased vessels ( $p<0.001$ ). In this study, a linear correlation was found between $\mathrm{HbAlc}$ level and CAD severity according to Syntax score $(p<0.001) .{ }^{13}$ In addition, the mean age of the patients were $58.1 \pm 10.4$ years and $91.9 \%$ (318) were males. Although the mean age in this study was similar to the above-mentioned study, the percentage of male patients $(67.5 \%)$ in this study was more balanced.

One of the confounding factors affecting $\mathrm{HbAlc}$ is the value of hemoglobin $(\mathrm{Hb})$ as it changes $\mathrm{HbAlc}$ levels. ${ }^{14} \mathrm{~A}$ low $\mathrm{Hb}$ value may lower the $\mathrm{HbAlc}$ level; this may show an association between CAD severity and lower HbAlc levels. In a study that included 119 acute coronary syndrome patients without diabetes, no significant difference was found for $\mathrm{HbAlc}$ values in multivariate logistic regression analysis in groups with Syntax score $\leq 22$ and Syntax score $>22$. In conclusion, this study found that $\mathrm{HbAlc}$ value was not an independent predictor of CAD severity in nondiabetic adult patients. ${ }^{10}$ However, in that study, the male gender ratio was very high and the mean hemoglobin value was low. This may have affected the study results. Another advantage of this study is that the mean hemoglobin values were within normal limits in both groups. In addition, no significant difference was found between the FFR groups in terms of $\mathrm{Hb}$ value in this study.

In a study including 299 people, who underwent CAG for suspected ischemia, there was a significant increase in the prevalence of CAD and the number of associated lesioned vessels with increasing $\mathrm{HbAlc}$ levels. The ideal cut-off value of $\mathrm{HbAlc}$ to predict the occurrence of CAD was found to be 5.6\% (sensitivity: $60.5 \%$, specificity: $52 \%$ ). ${ }^{15}$ Similarly, in the present study, the ideal cut-off value of $\mathrm{HbAlc}$ was determined as $5.55 \%$. However, HbAlc cut-off value that we found for the relationship between FFR lesion severity and HbAlc differs from the study mentioned above, with sensitivity $88.0 \%$ and specificity $53.85 \%$. FFR gives better information about lesion hemodynamics than CAG. This is one of the most important advantages of this study compared to other studies.

Despite the fact that there is the small number of patients included in the study, the statistical correlation between $\mathrm{HbAlc}$ levels and FFR severity supports that high $\mathrm{HbAlC}$ levels contribute to coronary lesion severity. Another limitation of the study was that the $\mathrm{HbAlc}$ value was based on a single measurement, so it may underestimate any relationship between $\mathrm{HbAlc}$ and FFR lesion severity.

\section{CONCLUSION}

$\mathrm{HbAlc}$, which shows the long-term glycemic index, may be a predictor of CAD severity in non-diabetic patients, independent of traditional cardiovascular risk factors. HbAlc corre- lates with fractional flow reserve lesion severity in nondiabetic adult patients.

\section{ETHICAL APPROVAL:}

Ethics Committee approval for this study was received from the Bakircay University Medicine Faculty (Decision No. 263).

\section{PATIENTS' CONSENT:}

Written informed consents were obtained from all patients included in the study.

\section{CONFLICT OF INTEREST:}

The authors declared no conflict of interest.

\section{AUTHORS' CONTRIBUTION:}

MK: Conception and design of the study, analysis and drafting of manuscript.

TG: Acquisition and interpretation of data, and critical revision.

\section{REFERENCES}

1. Knuuti J, Wijns W, Saraste A, Capodanno D, Barbato E, Funck-Brentano C, et al. 2019 ESC Guidelines for the diagnosis and management of chronic coronary syndromes: The task force for the diagnosis and management of chronic coronary syndromes of the european society of cardiology (ESC). Eur Heart J 2019; 41(3):407-7. doi.org/10.1093/eurheartj/ehz425.

2. Kawase $Y$, Matsuo H, Akasaka T. Clinical use of physiological lesion assessment using pressure guide wires: An expert consensus document of the Japanese association of cardiovascular intervention and therapeutics. Cardiovasc Interv Ther 2019; 34:85-96. doi.org/10.1007/s12928-018-0559-0.

3. Yıldırır A. Practical tips for the measurement of fractional flow reserve (FFR). Arch Turk Soc Cardiol 2011; 39(5):433-5 doi: 10.5543/tkda.2011.01686.

4. Xaplanteris P, Fournier S, Pijls NHJ, Fearon WF, Barbato E, Tonino PAL, et al. Five-year outcomes with pci guided by fractional flow reserve. $N$ Engl J Med 2018; 379(3):250-9. doi: 10.1056/NEJMoa1803538.

5. Scully TG, Toner L, Yeoh J, Farouque O, Yudi MB, Horrigan M, et al. Safety and long-term clinical outcomes of fractional flow reserve guided coronary revascularisation. Heart Lung Circ 2021; S1443-9506(21)00074-3. doi: 10.1016/j.hlc.2021.02.009.

6. Dar MI, Beig JR, Jan I, Shah TR, Ali M, Rather HA, et al. Prevalence of type 2 diabetes mellitus and association of $\mathrm{HbAlc}$ with severity of coronary artery disease in patients presenting as non-diabetic acute coronary syndrome. Egypt Heart J 2020; 72(1):66. doi: 10.1186/s43044-020-00101-0.

7. Timmer JR, Hoekstra M, Nijsten MW, van der Horst IC, Ottervanger JP, Slingerland RJ, et al. Prognostic value of admission glycosylated hemoglobin and glucose in nondiabetic patients with ST-segment elevation myocardial infarction treated with percutaneous coronary intervention/clinical perspective. Circulation 2011; 124:704-11.

8. Hong LF, Li XL, Guo YL, Luo SH, Zhu CG, Qing P, et al. Glycosylated hemoglobin Alc as a marker predicting the severity 
of coronary artery disease and early outcome in patients with stable angina. Lipids Health Dis 2014; 13:89. doi: 10.1186/1476-511X-13-89.

9. Ikeda N, lijima R, Hara H, Moroi M, Nakamura M, Sugi K. Glycated hemoglobin is associated with the complexity of coronary artery disease, even in non-diabetic adults. J Atheroscler Thromb 2012; 19(12):1066-72. doi: 10.5551/jat.13722.

10. Habib S, Ullah SZ, Saghir T. The association between hemoglobin Alc and the severity of coronary artery disease in non-diabetic patients with acute coronary syndrome. Cureus 2020; 12(1):e6631. doi:10.7759/cureus.6631.

11. Jianjun $Y$, Xiaohua $P$, Xuemei T, Gang H, Hailong W. Comparison of outcomes between fractional-flow-reserveand angiography-directed intervention in non-st elevation acute coronary syndrome. J Coll Physicians Surg Pak 2019; 29(3): 268-73. doi: 10.29271/jcpsp.2019.03.268.

12. Motor S, Dokuyucu R, Sefil F, Rifaioğlu MM, Yengil E, Ulutaş
$\mathrm{KT}$, et al. Relationship between $\mathrm{Hbalc}$ and blood glucose level in hemodialysis patients with diabetes mellitus. Dicle Med J 2013; 40(4):616-20. doi: 10.5798/diclemedj.0921.2013.04.0343.

13. Dutta B, Neginhal M, Iqbal F. Glycated hemoglobin (HbAlC) correlation with severity of coronary artery disease in non-diabetic patients - a hospital based study from North-Eastern India. J Clin Diagn Res 2016; 10(9):OC20-OC3. doi: 10. 7860/JCDR/2016/22378.8525.

14. Adeoye S, Abraham S, Erlikh I, Sarfraz S, Borda T, Yeung L. Anemia and hemoglobin Alc level: Is there a case for redefining reference ranges and therapeutic goals? $\mathrm{Br}$ J Med Pract 2014; 7(1):a706.

15. Ashraf $\mathrm{H}$, Boroumand MA, Amirzadegan A, Talesh SA, Davoodi G. Hemoglobin A1C in non-diabetic patients: An independent predictor of coronary artery disease and its severity. Diabetes Res Clin Pract 2013; 102(3):225-32. doi: 10.1016/j.diabres.2013.10.011. 